\title{
Erratum to: Testing the Universality of the Effects of the Communities That Care Prevention System for Preventing Adolescent Drug Use and Delinquency
}

\author{
Sabrina Oesterle • J. David Hawkins • \\ Abigail A. Fagan • Robert D. Abbott • \\ Richard F. Catalano
}

Published online: 16 June 2010

(C) Society for Prevention Research 2010

\section{Erratum to: Prev Sci}

DOI 10.1007/s11121-010-0178-1

The original version of this article unfortunately contained a mistake in Table 4. The correct observed mean number of delinquent acts in 8th grade for girls is 0.62 for CTC communities and 0.86 for control communities. The correct observed mean number of delinquent acts in 8 th grade for boys is 0.95 for CTC communities and 1.38 for control communities. The adjusted differences between CTC and control communities are statistically significant for both genders as correctly reported in the original version of the article.

The online version of the original article can be found at http://dx.doi. org/10.1007/s11121-010-0178-1.

S. Oesterle $(\bowtie) \cdot$ J. D. Hawkins $\cdot$ R. F. Catalano

Social Development Research Group, University of Washington,

9725 3rd Ave. NE, Suite 401,

Seattle, WA 98115, USA

e-mail: soe@uw.edu

\section{A. A. Fagan}

Department of Criminology and Criminal Justice,

University of South Carolina,

Columbia, SC, USA

R. D. Abbott

College of Education, University of Washington,

Seattle, WA, USA 